The Times last summer documenting the apparent ease with which childless women in their 20 s could obtain the operation. ${ }^{6}$ Investigation of private sector records may well have prompted the observation that sterilisation is an increasingly widespread solution to the contraceptive problems of the young. Public sector statistics, however, show quite the reverse.

The General Household Survey data show that fewer than $1 \%$ of single men and women in their 20 s seek a permanent end to their fertility, and among the married only where high parity has been achieved does the number rise appreciably. Service figures tell the same story. The steady increase noted by Bledin et al in the number of sterilisation procedures carried out on younger women between 1961 and the early 1970s has not continued. ${ }^{7}$ Though comparable figures are not available for men, operations performed on women under 30 each year have remained remarkably constant in the past decade and the overall increase is solely attributable to the rise in the number of operations performed in the over 30s. Nor is there any evidence, from sterilisation figures at least, of a widespread trend towards childlessness. In 1983 only $3 \%$ of couples with no children had elected to be sterilised. Typical candidates for sterilisation, men and women, are still married couples in their 30 s who have completed their families.

A further welcome change over the past decade or so in the timing of sterilisation of women deserves mention. Far fewer operations are now performed at the same time as another obstetric event, and far more are performed as interval sterilisations. The number of procedures carried out at the emotionally stressful time of childbirth or delivery fell from two thirds of total inpatient sterilisations of women in NHS hospitals in 1973 to fewer than a quarter 10 years later.

Whether the rising trend in sterilisation has now reached its ceiling is hard to tell. The high prevalence in the United States has been almost stationary over the past few years, and the pool of those in Britain who would be prepared to resort to surgery to control their fertility cannot be inexhaustible. On the other hand, the present pace of surgical procedures alone would maintain the current prevalence rate, and on past evidence the upturn in 1983 will almost certainly have been reinforced after the "pill scare" in the autumn of that year. Inpatient figures for NHS hospitals are not available for 1984 , but family planning clinics reported a $32 \%$ increase in uptake in sterilisation of women and an $18 \%$ increase in vasectomy between 1983 and 1984. In addition, new potentially reversible methods of sterilisation are now being developed which could remove the main drawback of this method of family planning. It seems at least likely that the 1976 forecast of one third of married couples sterilised before the age of $35^{4}$ will become a reality.

Clearly the rising numbers of those electing to be sterilised raise important questions about counselling. Yet there seem no real grounds for the alarm raised in some quarters over the capacity of existing counselling services to cope. Research shows that those at high risk of regret (the target group of sterilisation counselling) are more likely to be younger ${ }^{8-11}$ and to have been sterilised at times of emotional trauma such as childbirth and abortion, ${ }^{1213}$ and the evidence suggests that proportionately fewer people are falling into these categories, not more.

Counselling is particularly important in the case of voluntary sterilisation, where the decision must be regarded as irrevocable; and adequate provision of relevant information is vital in every case. But a recent report from the Policy Studies Institute shows that lengthy counselling insisted on indiscriminately is not necessarily in the best interest of every client. ${ }^{14}$ To give full counselling to all might be as intrusive as to withhold it from the few who need it would be neglectful However carefully doctors screen their patients, a small bu民̨ tragic proportion of those who undergo the operation wilf subsequently experience regret. But even the very bes 5 . counselling cannot realistically prepare for every eventuality in life.

Research Officer,
Family Planning Information Service,
London W1N 7RJ

Kaye WeLling\$্

1 Stepan J, Kellogg EH, Piotrow PT. Legal trends and issues in voluntary sterilization Populaino

reports. Ser E. No 6. Baltimore. USA: Johns Hopkins University, 1981.
Office of Population Censuses and Surveys. General household survey 1983. London: HMSO, 1985

3 Bone M. Family planning services in England and Wales. London: HMSO, 1973.

4 Dunnell K. Family formation 1976. London: HMSO, 1979.

4 Dunnell K. Family formation 1976. London: HMSO, 1979.

Newton J. The changing pattern of male and female sterilisation. In: Roe J, ed. Sterilisation services, organisation and procedures. London: Birth Control Trust, 1983.

6 Toomey C. Sterilization: an informed decision? The Times 1985 Aug 9:9 (cols 1-7).

Bledin KD, Beral V, Ashley JSA. Recent trends in sterilisation in women. Health Trends 1978;10:84-7.

8 Divers WA. Characteristics of women requesting reversal of sterilisation. Fertil Steril 1984;4 233-6.

9 Howard G. Who asks for vasectomy reversal and why? Br Med f 1982;285:490-2.

10 Wright AF. How women felt about their sterilization-a follow up of 368 patients in a generat. practice. 7 R Coll Gen Pract 1981;31:598-604.

Winston RML. Why 103 women asked for reversal of sterilisation. Br Med f 1977;ii:305-7.

12 Jablensky A. Mental health and female sterilisation; report of a WHO collaborative study. $\mathcal{I}$ BiosoO

Sa 1984;16:1-21.
13 Savage WD. Abortion and sterilisation-should the operations be combined? British fournal ox Family Planning 1981;7:8-12.

14 Allen I. Counselling services for sterilisation, vasectomy and termination of pregnancy. London: Polic $\vec{D}$ Studies Institute, 1985

\section{Symptoms limiting exercise in chronic heart failure}

The symptoms which limit exercise in patients with heare failure are notoriously difficult to evaluate. The perception of shortness of breath may vary among patients. Classic teach $₹$ ing has been that breathlessness in patients with heart disease is due to raised left atrial pressure and fatigue due to an inadequate increase of cardiac output on exercise. In acute heart failure this simple view may be correct. Certainly breathlessness and the development of pulmonary oedem do relate to left atrial pressure. Paraoxysmal nocturnat dyspnoea and orthopnoea are features of an overexpandeक circulation. Drugs which lower the left atrial pressure almost always relieve breathlessness.

The primary event initiating the clinical syndrome o chronic heart failure is ventricular dysfunction. Not une reasonably, physicians have assumed that exercise capacit $\overline{\bar{X}}$ would be related to the severity of the left ventricular dysfunction. Recent studies, however, have shown that this is not true. When patients with heart failure are assessed theif exercise capacity cannot be predicted from estimates of leff ventricular ejection fraction or end diastolic dimensions. either at rest ${ }^{1-4}$ or on peak exercise. ${ }^{3}$ Furthermore, the mechanism by which these patients increase cardiac outpu审 on exercise varies with the aetiology of the heart failure. ${ }^{5}$ I patients with idiopathic dilated cardiomyopathy the stroke volume is increased by a reduction of the ventricular volume at end systole with little change in dimensions at ens diastole - an increase in the ejection fraction. In patients wit ischaemic heart disease the stroke volume is increased by enlargement of the size of the heart at end diastole and almost 
no change in dimensions at end systole-so that the ejection fraction is decreased or little changed.

The origin of symptoms in these patients is less clear than in patients with acute heart failure. The classic teaching has been challenged by recent research. ${ }^{6-9}$ The feeling of breathlessness appears to be independent of changes in left atrial pressure as estimated from the pulmonary capillary wedge pressure. No correlation exists between the wedge pressure at rest or during maximal exercise and maximal oxygen consumption reached at the end of symptom limited exercise. ${ }^{79}$ The symptom which terminates exercise depends on the type of exercise performed despite the peak wedge pressure being the same. ${ }^{9}$ Rapid forms of exercise tend to result in breathlessness, whereas slower, prolonged forms of exercise come to an end because of fatigue. ${ }^{9}$ Furthermore, long term drug studies show that an improvement in exercise capacity is often but not invariably associated with an improvement in exercise haemodynamics and a fall in pulmonary capillary wedge pressure. ${ }^{10}$ Short term, vasodilator and inotropic agents almost always improve the haemodynamic indices and lower the pulmonary capillary wedge pressure but usually they do not increase exercise capacity either immediately or long term. ${ }^{11-13}$ In one study amrinone given acutely to patients with severe heart failure did increase exercise capacity and peak oxygen consumption-but the pulmonary capillary wedge pressure also increased, indicating that a high pulmonary capillary wedge pressure had not been the factor initially limiting exercise. ${ }^{14}$

The postulated link between a raised left atrial pressure and breathlessness in chronic heart failure is also weakened by the lack of any obvious physiological mechanism. Juxtapulmonary capillary receptors ("J" receptors) may be activated by stiffening of the lungs, as may occur with accumulation of interstitial fluid, and this causes tachypnoea and the feeling of breathlessness. ${ }^{15}$ Decreased lung compliance does not, however, correlate with the degree of dyspnoea ${ }^{16}{ }^{17}$ and patients with left ventricular dysfunction develop only small increases in pulmonary blood volume and pulmonary extravascular fluid. ${ }^{18}$

An alternative explanation relates to the many and complex metabolic changes during exercise. ${ }^{9}$ The blood flow through skeletal muscles is reduced in patients with heart failure. ${ }^{19}$ A metabolic acidosis develops during rapid forms of exercise, and this may stimulate peripheral chemoreceptors and contribute to the hyperventilatory response and the feeling of breathlessness.'

In patients limited by fatigue several studies have suggested that the cause is an inadequate oxygen supply to skeletal muscle. ${ }^{1920}$ During maximum exercise the oxygen content of blood in the femoral vein is negligible. ${ }^{21}$ Wilson $e t$ al showed that patients with chronic heart failure developed fatigue when the underperfusion of muscle reached a critical level and concluded that maximal exercise capacity of patients with heart failure was due to an impaired nutritive flow to the skeletal muscle. ${ }^{19}$ The mechanism may be an intracellular acidosis, accumulation of lactate, or depletion of phosphocreatinine. ${ }^{22}$ Persistent changes in the function of skeletal muscle also occur in chronic heart failure and may contribute to exercise limitation in these patients. ${ }^{23}$

What these research findings show, then, is that the limitation of exercise and the feelings of breathlessness or fatigue in patients with chronic heart failure have multifactorial mechanisms. Their symptoms should not be related solely to an altered haemodynamic response to exercise. Which symptom is limiting in an individual patient will depend on the different mechanisms influencing neural and metabolic signals from exercising muscle and the response of more central receptors.

D P LIPKIN

Research registrar

Philip A PoOle-Wilson

Professor of cardiology

Cardiothoracic Institute and National Heart Hospital,

London WIN 2DX

1 Franciosa JA, Park M, Levine TB. Lack of correlation between exercise capacity and indexes of resting left ventricular performance in heart failure. Am $\mathcal{F}$ Cardiol 1981;47:33-9.

2 Enger R, Ray R, Higgins CB, et al. Clinical assessment and follow up of functional capacity in patients with chronic congestive cardiomyopathy. Am J Cardiol 1982;49:1832-7.

3 Higgenbotham MB, Morris KG, Conn EH, Coleman RE, Cobb FR. Determinants of exercise performance among patients with severe left ventricular dysfunction. $A m \mathcal{F}$ Cardiol 1983;51: $52-60$.

4 Baker NJ, Wilen MM, Boyd CM, Dinh H, Franciosa JA. Relation of right ventricular ejection fraction to exercise capacity in chronic left ventricular failure. Am F Cardiol 1984;54:596-9.

5 Shen WF, Roubin GS, Hirasawa $\mathrm{K}$, et al. Left ventricular volume and ejection fraction response to exercise in chronic congestive heart failure: difference between dilated cardiomyopathy and previous myocardial infarction. Am f Cardiol 1985;55:1027-31.

6 Franciosa JA, Ziesche S, Wilen M. Functional capacity in patients with chronic left ventricular failure: relationship of bicycle exercise performance to clinical hemodynamic characterization. Am 7 Cardiol 1979;67:460-6.

7 Franciosa JA, Leddy CL, Wilen M, Schwartz DE. Relation between hemodynamic and ventilatory responses in determining exercise capacity in severe congestive heart failure. $A m \mathcal{F}$ Cardiol 1984;53:127-34.

8 Francis GS, Goldsmith SR, Cohn JN. Relationship of exercise capacity to resting left ventricular performance and basal plasma norepinephrine levels in patients with congestive heart failure Am Heart $\mathcal{F}$ 1982;104:725-31.

9 Lipkin DP, Poole-Wilson PA. Factors determining symptoms in chronic heart failure. Comparison of a fast and slow exercise test. $\mathrm{Br}$ Heart $\mathcal{J}$ (in press

10 Franciosa JA, Goldsmith SR, Cohn JN. Contrasting immediate and long term effects of isosorbide dinitrate on exercise capacity in congestive heart failure. Am J Cardiol 1980;69:559-66.

11 Packer $M$. Conceptual dilemmas in the classification of vasodilator drugs for severe heart failure. Am F Med 1984;76:3-13.

12 Franciosa JA, Dunkman B, Leddy CL. Hemodynamic effect of vasodilators and long term response in heart failure. Fournal of the American College of Cardiology 1984;3:1521-30.

13 Lipkin DP, Poole-Wilson PA. Treatment for chronic heart failure: a review of recent drug trials. BrMed f 1985;291:993-6.

14 Siskind SJ. Sonnenblick EH, Forman R, Schever J, LeJemtel TH. Acute substantial benefit of inotropic therapy with amrinone on exercise hemodynamics and metabolism in severe congestive heart failure. Circulation 1981;64:966-73.

15 Pantol AS. Mechanisms of stimulation of type J pulmonary receptors. $\mathcal{F}$ Physiol 1969;203:51 1-32. 6 Frank RN, Cugell DW, Caensler EA, Ellis LB. Ventilatory studies in mitral stenosis. Am $\mathcal{J}$ Med 1953:15:60-75

17 Haywood GW, Knott JMS. The effect of exercise on lung distensibility and respiratory work in mitral stenosis. Br Heart f 1955; 17:303-11.

18 Austin SM, Schreiner BF, Shah PM, Yu PN. Acute effects of increased pulmonary vascular distending pressure on pulmonary blood volume and pulmonary extravascular fluid volume in man. Circulation 1976;53:356-63.

19 Wilson JR, Martin JL, Schwartz D, Ferraro N. Exercise intolerance in patients with CHF: role of impaired nutritive flow to skeletal muscle. Circulation 1984;69:1079-87.

20 Donald $\mathrm{KW}$, Wormold PN, Taylor SH, Bishop JM. Changes in the oxygen content of femoral venous blood and leg based flow during leg exercise in relation to the cardiac output response.

21 Canepa-Anson R, Poole-Wilson PA. Vasodilator therapy in left ventricular failure. Effect of prazosin on the distribution of blood flow. Br $\mathcal{A}$ Clin Pract 1984; suppl 29:30-3.

22 Wilson JR, Fink L, Mario J, et al. Evaluation of energy metabolism in skeletal muscle of patients with heart failure with gated phosphorus-31 nuclear magnetic resonance. Circulation 1985;71:

23 Lipkin DP, Jones DA, Round J, Poole-Wilson PA. Maximal force, type and enzymatic activity in quadriceps of patients with severe heart failure; a mechanism for reduced exercise capacity. $\mathrm{Br}$ Heart 7 1985;54:622A

\section{The Nuffield report: a signpost for pharmacy}

Two years ago we reported the setting up of the Nuffield Foundation Pharmacy Inquiry and discussed some of the problems facing our pharmaceutical colleagues in the various branches of their profession. ${ }^{1}$ The report of the committee of inquiry, on which there were three medical members, has now been published and, as we forecast, its conclusions and recommendations are far reaching. ${ }^{2}$ The face of pharmacy will change appreciably over the next decade if they are put into effect, and they will have an impact on other health professions, including medicine.

The general tone of the report is positive and optimistic, 